\title{
Interleukin 1 Gene Expression in Cultured Human Keratinocytes Is Augmented by Ultraviolet Irradiation
}

\author{
Thomas S. Kupper, Anne O. Chua, Patrick Flood, Joseph McGuire, and Ueli Gubler \\ Departments of Dermatology and Pathology/Howard Hughes Medical Institute, Yale University School of Medicine, New Haven, \\ Connecticut 06510; Department of Molecular Genetics, Hoffmann-LaRoche Inc., Nutley, New Jersey 07110
}

\begin{abstract}
Interleukin 1 (IL-1) is a family of polypeptides initially found to be produced by activated monocytes and macrophages that mediate a wide variety of cellular responses to injury and infection. Epidermal epithelial cells (keratinocytes) produce "epidermal cell-derived thymocyte activating factor" or ETAF, which has been recently shown to be identical to IL-1. Human epidermis is normally exposed to significant amounts of solar ultraviolet radiation. Certain ultraviolet wavelengths (UVB, 290-320 nm) are thought to be responsible for most of the immediate and long-term pathological consequences of excessive exposure to sunlight. In this study, we asked whether exposure to UVB irradiation induced IL-1 gene expression in cultured human keratinocytes. Cultured human keratinocytes contain detectable amounts of $\mathrm{IL}-1 \boldsymbol{\alpha}$ and $\beta$ mRNA and protein in the absence of apparent stimulation; these levels could be significantly enhanced $6 \mathrm{~h}$ after exposure to $10 \mathrm{ng} / \mathrm{ml}$ of 12-O-tetradecanoyl-phorbol13-acetate (TPA). Exposure to UVB irradiation with an emission spectrum comparable to that of sunlight (as opposed to that of an unfiltered artificial UV light source) significantly increased the steady state levels IL-1 $\alpha$ and $\beta$ mRNA in identical populations of human keratinocytes. This was reflected in the production of increased IL-1 activity by these cultures in vitro. In the same cell population, exposures to UVB irradiation did not alter the level of actin mRNA; therefore, the effect of UV irradiation on IL-1 represents a specific enhancement of $I L-1$ gene expression. Local increases of IL-1 may mediate the inflammation and vasodilation characteristic of acute UVB-injured skin, and systemic release of this epidermal IL-1 may account for fever, leukocytosis, and the acute phase response seen after excessive sun exposure.
\end{abstract}

\section{Introduction}

Human monocytic interleukin 1 (IL-1) consists of two discrete molecular species termed IL-1 $\alpha$ and IL-1 $\beta(1,2)$. Although the proteins encoded by these genes bear only $25 \%$ homology, both appear to bind to the same receptor with comparable affinities and both mediate the same biological effects both in vivo and in vitro $(3,4)$. The production of IL-1 by monocytes and macrophages is increased under conditions that may be interpreted as injurious to the host; this observation, coupled with the multiplicity of its effects on target tissues, has led to speculation that

Address correspondence to Dr. Kupper, Department of Dermatology, Yale University School of Medicine, New Haven, CT 06510.

Received for publication 22 December 1986.

J. Clin. Invest.

(C) The American Society for Clinical Investigation, Inc.

0021-9738/87/08/0430/07 \$2.00

Volume 80, August 1987, 430-436 production and release of IL-1 is a fundamentally important host response to stress (5). Recently, it has been established that other cells can make factors with IL-1-like activity (6-8). Specifically, keratinocytes produce a molecule biochemically and functionally similar to IL-1 (8), and we have recently shown that this "epidermal cell-derived thymocyte activating factor" (ETAF) 1 is identical to monocytic IL-1 at the molecular level (9). Keratinocyte ETAF release, like monocytic IL-1 release, is increased by injurious stimuli, including bacterial lipopolysaccharide (LPS), silica, thermal energy, phorbol esters, and mechanical disruption (10-12). However, it has not been established whether such stimuli increase the release of IL-1 from keratinocytes by damaging cells and allowing passive release of intracellular contents, or whether these stimuli specifically enhance IL-1 gene expression. The observation that both IL- $1 \alpha$ and $\beta$ polypeptides lack a hydrophobic sequence consistent with that observed for other secreted polypeptides has led some investigators to suggest that IL-1 may be only released upon cytolysis (13). Since it has been shown that mRNAs encoding for ETAF activity are completely homologous to monocytic IL- $1 \alpha$ and $\beta$ mRNAs (9), the induction of keratinocyte gene expression by the above stimuli can be assessed directly.

Human keratinocytes are uniquely exposed to UVB irradiation by virtue of their anatomic location, and solar UVB irradiation is the most likely environmental source of injury to skin in the absence of physical trauma. Therefore, it is not surprising that investigators have examined the effect of ultraviolet wavelength (UVB) irradiation on a variety of parameters in keratinocytes. Studies have reported that UVB irradiation increases (14), decreases (15), or has no effect (16) on the production of ETAF by keratinocytes in vivo and in vitro. Most of these studies, however, did not report the spectral power distributions of UVB light under their respective conditions, and it is possible that variations in this parameter influence the production of or release of ETAF from cells.

Less than $1 \%$ of the solar radiation reaching the earth is composed of ultraviolet wavelengths $(290-400 \mathrm{~nm})$, and $<2 \%$ of this UV light is in the UVB range (290-320 nm; reference 19). These wavelengths, however, account for the immediate and long-term deleterious effects of sun exposure (18). Wavelengths of 290-300 $\mathrm{nm}$ are most effective at inducing erythema in human skin ("minimal erythemal dose" or MED); $20 \mathrm{~mJ} /$ $\mathrm{cm}^{2}$ of $300 \mathrm{~nm}$ light constitutes a single MED, while $200 \mathrm{~mJ} /$ $\mathrm{cm}^{2}$ of $310 \mathrm{~nm}$ light is required to induce equivalent erythema (e.g., one MED; reference 19). Although light of these wavelengths (290-300) reaches the earth in small quantities, artificial UVB light sources used for most in vitro experiments emit significant amounts of these short UVB wavelengths. Accordingly,

1. Abbreviations used in this paper: ETAF, epidermal cell-derived thymocyte activating factor; MED, minimal erythemal dose. 
it is clear that light sources with different spectral emissions may have markedly different effects on cultured cells, even when the total energy delivered to the cells is equal.

In the present study, we asked whether amounts of UVB irradiation that approximate prolonged in vivo exposure to sunlight, both in terms of energy and spectral range (16), would enhance ETAF/IL-1 production by keratinocytes and whether this enhancement occurred at the level of gene expression.

\section{Methods}

Keratinocytes. Human foreskin keratinocytes were grown in complete Dulbecco's minimal essential medium (DMEM) with $20 \%$ fetal calf serum (FCS) and $10^{-6} \mathrm{M}$ hydrocortisone as previously described (20). Hydrocortisone was omitted from the culture medium for at least $96 \mathrm{~h}$ before the initiation of experimental conditions.

Ultraviolet irradiation. A bank of four bulbs (FS20, Westinghouse Electric Corp., Pittsburgh, PA) were used to irradiate cells. The energy delivered to the confluent cell layer was determined before each experiment by measuring the radiant output of the FS20 bulbs through one layer of tissue culture plastic $(6 \mathrm{~cm}$ petri dish, Corning Glass Works, Corning, NY) containing $4 \mathrm{ml}$ of DMEM with $20 \%$ FCS using a UVX digital radiometer (Ultraviolet Products, Inc., San Gabriel, CA) and a UVX-31 probe with peak absorbance at $310 \mathrm{~nm}$. Timed exposures corresponding to 100,200 , and $300 \mathrm{~mJ} / \mathrm{cm}^{2}$ were calculated for each experiment and cultures were exposed under identical conditions (i.e., through one layer each of tissue culture medium and plastic). Irradiated medium was removed, fresh tissue culture medium $(4 \mathrm{ml})$ was added, and the dishes were cultured for $24 \mathrm{~h}$ at $37^{\circ} \mathrm{C}$ in a $95 \%$ air $/ 5 \% \mathrm{CO}_{2}$ incubator. Viability at $24 \mathrm{~h}$ (propidium iodide exclusion) was $>90 \%$ under all conditions. Conditioned medium was then decanted and the adherent cells were mechanically removed from the dishes, resuspended in $4 \mathrm{ml}$ of tissue culture medium, and lysed by three cycles of freeze thawing, sonicated, and filtered through a $42-\mu \mathrm{m}$ Millipore filter (Millipore Corp., Bedford, MA).

$I L-1$ assay. Recombinant human IL- $1 \alpha$ was obtained from Dr. Peter Lomedico (Hoffmann-LaRoche) and was used as a standard for all assays. D10.G4.1 cells were generously provided by Dr. C. Janeway, Jr. (Yale University), and were maintained as previously described (21). D10 cells were used at least $10 \mathrm{~d}$ after feeding with antigen, feeder cells, and TCGF. These "resting" D10 cells were washed three times and diluted to a final concentration of $10^{5}$ cells/ml in Click's Eagle's Hanks' amino acids medium with 5\% FCS added. Monoclonal 3D3 antibody (22) was used at a final concentration of 1:1,000. Triplicate cultures of D10 cells, 3D3 antibody, and serial dilutions of keratinocyte-conditioned medium or cell lysate were incubated in a final volume of $200 \mu \mathrm{l}$ in 96-well microtiter plates (Costar Data Packaging, Hialeah, FL) for $72 \mathrm{~h}$ at $37^{\circ} \mathrm{C}$ in a $5 \%$ $\mathrm{CO}_{2} / 95 \%$ air incubator. $3 \mathrm{~h}$ before harvest, $1 \mu \mathrm{Ci} /$ well of $\left[{ }^{3} \mathrm{H}\right]$ thymidine was added and cultures were harvested with a MASH (Cambridge Technology, Inc., Cambridge, MA). Incorporation of $\left[{ }^{3} \mathrm{H}\right]$ thymidine into DNA was measured by scintillation spectrometry.

SI nuclease protection assay. cDNA clones for human IL-1 $\alpha$ (23) and IL-1 $\beta$ (2) were first modified by deleting one of the homopolymeric tails used in the original cloning. S1 probes free of homopolymeric tails were then generated for IL- $1 \alpha$ by labeling a 960-bp Hind III-Pst I fragment at the Hind III site in the strand complementary to the mRNA and for IL-1 $\beta$ for labeling an 855 bp Hind III-Taq I fragment at the Hind III site in the strand complementary to the mRNA. The specific activities of these probes were determined for each preparation and were usually on the order of 1-2 $\times 10^{4} \mathrm{dpm} / \mathrm{fmol}$. 2-5 fmol of end labeled $\alpha$ and $\beta$ probe were hybridized separately to indicated amounts of total RNA sample in $80 \%$ deionized formamide, $0.4 \mathrm{M} \mathrm{NaCl}, 1 \mathrm{mM}$ EDTA, 40 mM Pipes, pH 6.8 at $52^{\circ} \mathrm{C}$ overnight. After this incubation, each sample was digested for $60 \mathrm{~min}$ at $37^{\circ} \mathrm{C}$ with $100 \mathrm{U}$ of S1 nuclease (9). The products were subsequently analyzed on a $5 \%$ sequencing gel as previously described (9). To determine the relative mRNA levels, films were scanned at $550 \mathrm{~nm}$ and areas under the peaks were calculated by weighing. The values obtained were corrected for the fact that the specific activity of the IL- $1 \alpha$ probe was 1.9 times that of the IL- $1 \beta$ probe.

Slot blot assay. Total RNA $(14 \mu \mathrm{g})$ was denatured at $65^{\circ} \mathrm{C}$ in $0.9 \mathrm{M}$ $\mathrm{NaCl} / 0.09 \mathrm{M} \mathrm{Na}$ citrate (6× SSC)-7.4\% formaldehyde for $10 \mathrm{~min}$ and filtered onto a sheet of nitrocellulose prewetted with $6 \times$ SSC, using a slot blot apparatus (Schleicher \& Schuell, Inc., Keene, NH). Four different amounts of RNA (see above) were applied per sample. There is no need to compensate for the lower amounts of RNA spotted by adding carrier RNA(Chua, A. O.Unpublished observations). The membrane was probed with a nick translated chicken actin cDNA clone, washed, and exposed to $\mathrm{x}$-ray film. The autoradiogram was scanned at $550 \mathrm{~nm}$ and peak areas (determined by weighing) were plotted as a function of RNA amount loaded per slot. Linear regression analysis yields a value for the slope of the line going through the four points and can be used as a measure for the relative actin mRNA levels in the sample tested.

\section{Results}

We have previously reported that human keratinocytes produce both IL-1 mRNA and protein in the absence of intentional stimulation (9). This constitutive production was not altered by the addition of polymixin $B$ and therefore was thought not to be due to low levels of contaminating endotoxin. For all subsequent studies, secondary cultures of human foreskin keratinocytes were grown to confluence as previously described (20). Samples of cells and tissue culture medium under these conditions were endotoxin free as judged by the limulus lysate assay. Keratinocytes grown in this fashion are homogeneous and produce keratins characteristic of epidermis (20).

Since cultured keratinocytes, unlike monocytes, contain significant steady state levels of IL- $1 \alpha$ and $\beta$, we considered the possibility that keratinocyte IL-1 production was already maximally induced in our culture system. In an attempt to further induce IL-1 gene expression, TPA was added to confluent cultures of human keratinocytes (final concentration, $10 \mu \mathrm{g} / \mathrm{ml}$ ) and, $6 \mathrm{~h}$ later, cells were harvested and total RNA was extracted. Total RNA was then analyzed with an S1 nuclease protection assay (19) using cDNA probes for human monocyte IL- $1 \alpha$ and $\beta$. The sizes of the protected fragments in this assay are 210 nucleotides for IL- $1 \alpha$ (corresponding to the coding region for amino acids 64-134 of the complete IL- $1 \alpha$ precursor) and 525 nucleotides for IL- $1 \beta$ (corresponding to the coding region for amino acids $133-269$ of the complete IL- $1 \beta$ precursor plus 116 nucleotides of the $3^{\prime}$ untranslated region). In addition, the IL$1 \alpha$ probe very reproducibly gives rise to a secondary fragment of 125 nucleotides that is due to an S1 sensitive site within the probe (see also reference 9). Fig. 1 shows this analysis, using LPS stimulated monocyte RNA as a positive control (lane 3) and porcine intestine RNA as a negative control (lane 4). Lane 1 shows that significant IL- $1 \alpha$ mRNA and somewhat less IL- $1 \beta$ mRNA is present in human keratinocytes in the absence of stimulation. Lane 2 indicates that PMA significantly enhances both IL- $1 \alpha$ and $\beta$ mRNA by nine and sevenfold, respectively, as determined by scanning densitometry. Total protein and cell number were identical in induced and uninduced cultures (not shown). To confirm that PMA did not nonspecifically enhance levels of mRNAs, slot blot analysis of RNA from both uninduced and PMA-induced keratinocytes was performed using an actin cDNA probe. Fig. 2 shows that PMA did not increase the level of actin mRNA and in fact led to a modest reduction of this RNA after $6 \mathrm{~h}$ as compared with control values; this was confirmed by linear regression analysis. Therefore, while human keratinocytes contain both $\alpha$ and $\beta$ mRNA in the absence of stimulation, PMA significantly enhances the steady state levels 


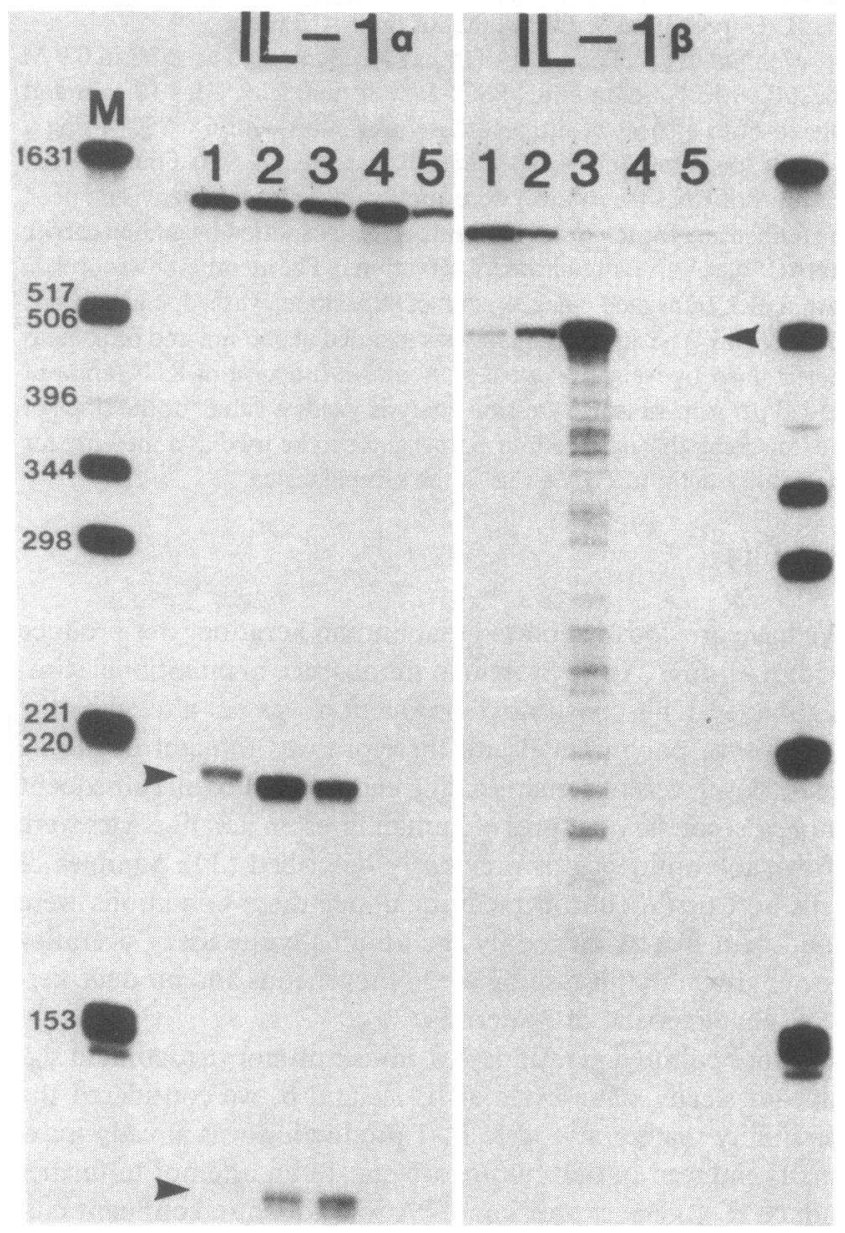

Figure 1. S1 nuclease protection assay to determine relative levels of IL- $1 \alpha$ and IL- $1 \beta$ mRNAs in cultured HFKs exposed to $10 \mathrm{ng} / \mathrm{ml}$ PMA. Protected fragments are indicated by arrows. Lane 1, untreated HFK, $18 \mu \mathrm{g}$; lane 2, HFK treated with PMA for $6 \mathrm{~h}, 18 \mu \mathrm{g}$; lane 3, LPS-stimulated human peripheral blood leukocyte RNA, $8 \mu \mathrm{g}$, positive control; lane 4, pig intestine RNA, $30 \mu \mathrm{g}$, negative control; lane 5 , no RNA. $M$, marker, pBR 322 Hinf I. See Methods for further details.

of both mRNAs. In addition, these data confirm our previous reports (9) that IL-1 $\alpha$ is not a minor species of IL-1 in keratinocytes and may in fact be the predominant IL-1 in epidermis.

Ultraviolet light from artificial sources delivers significant energy at wavelengths of $290-300 \mathrm{~mJ} / \mathrm{cm}^{2}$ (Fig. 3); however, the earth's atmosphere absorbs virtually all of these wavelengths (17). It was inadvertently found that by exposing cultured keratinocytes to an artificial UVB light source through tissue culture plastic and medium, the relative intensity of UVB wavelengths reaching the adherent cell layer is similar to those of sunlight reaching human epidermis. To exclude the possibility that photoactivation of tissue culture medium could induce IL-1 gene expression in keratinocytes, UVB-irradiated tissue culture medium was added to unirradiated keratinocytes and no increased IL-1 production or release ensued (unpublished observations).

Cultures were exposed to defined amounts of UVB light such that the total energy delivered to the cells (measured after transmittance through plastic and tissue culture fluid) was 100, 200, or $300 \mathrm{~mJ} / \mathrm{cm}^{2}$. Survival of these cells at $24 \mathrm{~h}$ was $>90 \%$ under all conditions (not shown). Cells were harvested either 1 or $6 \mathrm{~h}$ after exposure to UVB light, and total RNA was extracted as previously described (9). Cells irradiated through saline alone

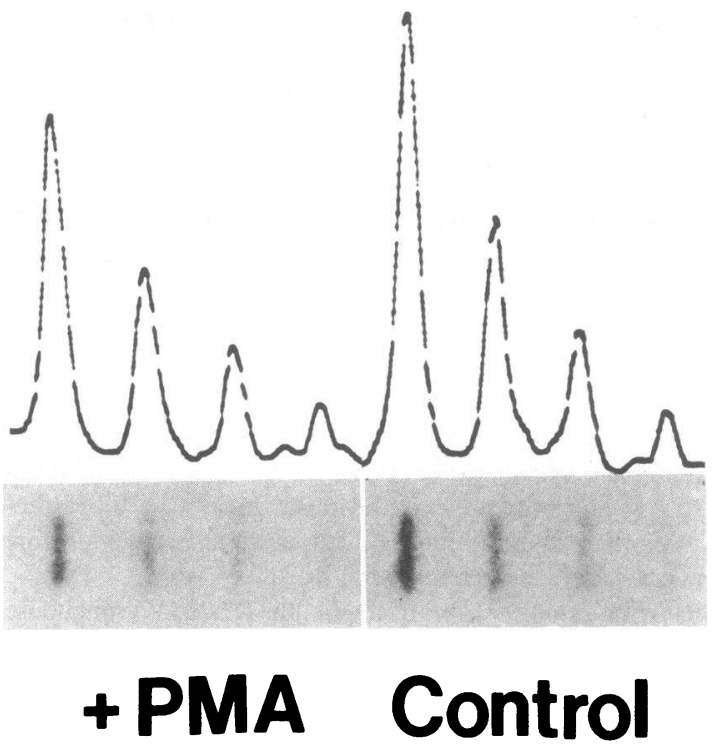

Figure 2. Slot blot analysis to determine relative levels of actin mRNA in uninduced and PMA induced HFKs. The lower portion of the figure shows the autoradiogram of the slotblots. For each sample, from left to right were loaded $6,3,1.5$, and $0.75 \mu \mathrm{g}$ of total RNA. The upper portion shows the scan of the film at $550 \mathrm{~nm}$.

(that is, without tissue culture plastic or medium) were much more susceptible to UVB-induced damage, with significant cell death occurring after $200 \mathrm{~mJ} / \mathrm{cm}^{2}$ and total cell destruction occurring at $300 \mathrm{~mJ} / \mathrm{cm}^{2}$.

Fig. 4 shows that HFK, in the absence of apparent stimulation, contain mRNA identical to IL $-1 \alpha$ and $\beta$ mRNA from LPS-stimulated peripheral blood leukocytes. Exposure of these HFK to $100 \mathrm{~mJ} / \mathrm{cm}^{2}$ of UVB irradiation led to a modest increase in the levels of both IL $-\alpha$ and $\beta$ mRNA $1 \mathrm{~h}$ after irradiation (Fig. 4 and Table I). By $6 \mathrm{~h}$ after this exposure, however, IL-1 $\alpha$ mRNA had fallen to steady state levels while the roughly twofold increase in IL- $1 \beta$ mRNA persisted. This modest increase of IL$1 \alpha$ and $\beta$ mRNA levels was also seen $1 \mathrm{~h}$ after exposure to either

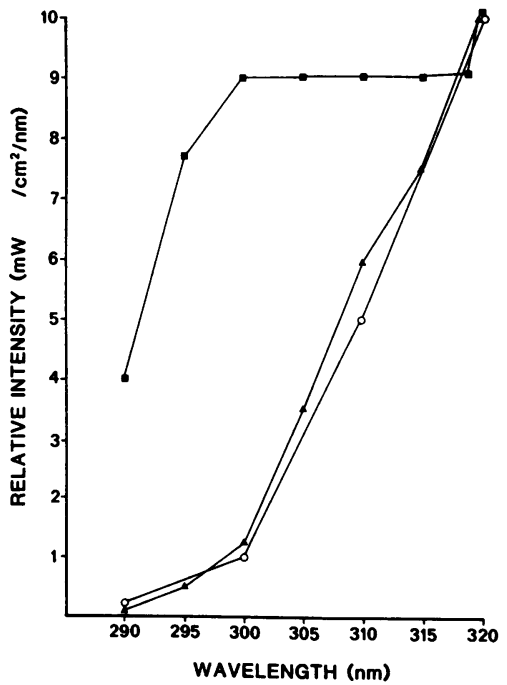

Figure 3. Spectral power distributions (relative intensity vs. wavelength) of Westinghouse FS20 sunlamp (closed squares); FS20 sunlamp transmitted through tissue culture medium and tissue culture plastic (closed circles); and terrestrial radiation (open circles); over the UVB range (290-320). The relative intensities of 325- and 330-nm wavelengths (formerly UVA) for "filtered" FS20 radiation are 6.0 and 3.8 , respectively; therefore, a small proportion of the energy delivered to the cells consisted of UVA wavelengths. Wavelengths $>330 \mathrm{~nm}$ are not emitted in significant amounts by this light source. 


\section{$\mathrm{IL}-1 \mathrm{a} \ldots \quad \mathrm{IL}-1 \beta$}

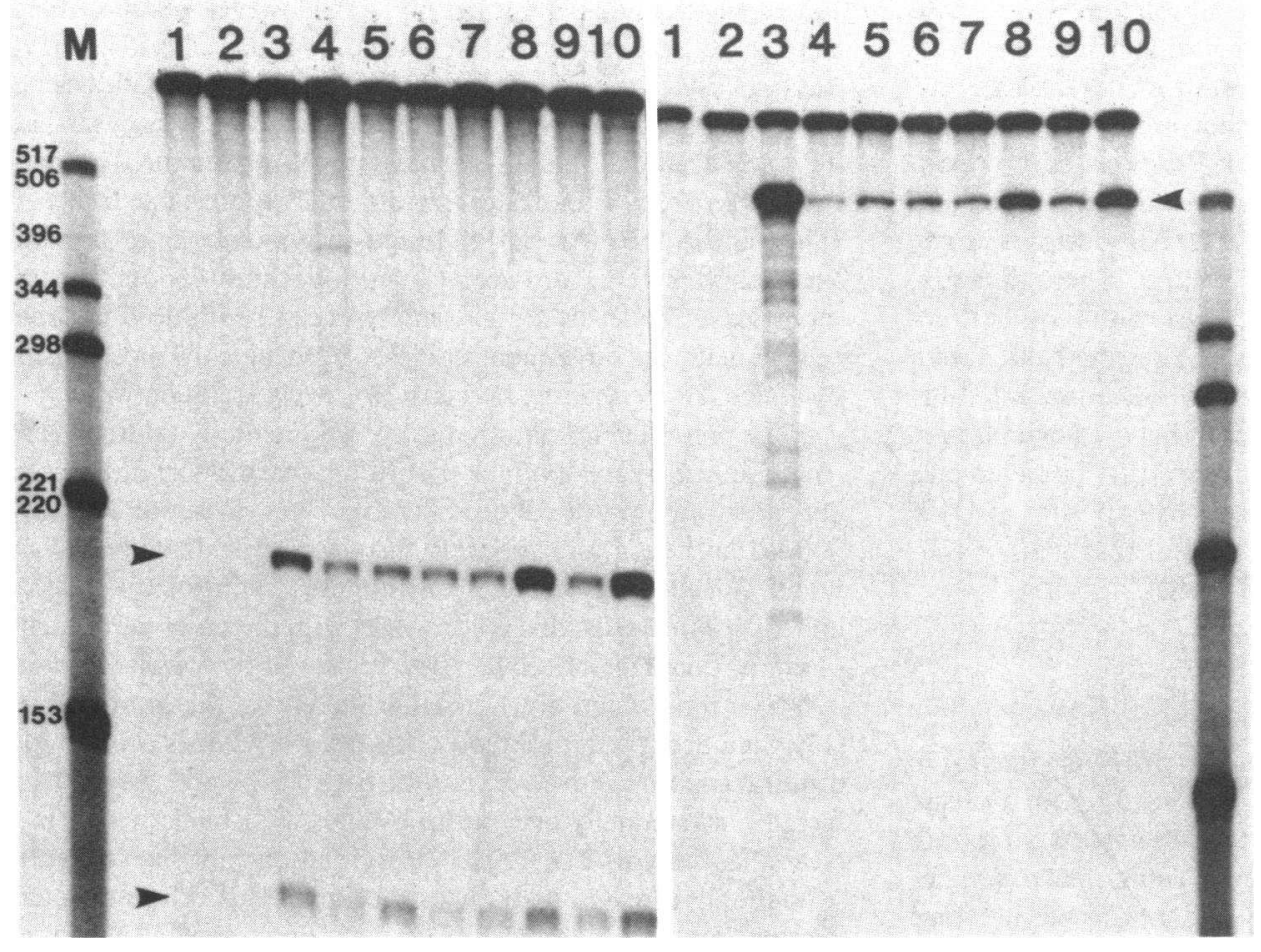

Figure 4. S1 nuclease protection assay to determine relative levels of IL- $1 \alpha$ and IL- $1 \beta$ mRNAs in cultured HFKs exposed to different doses of UVB irradiation. Protected fragments are indicated by arrows. Lane 1 , no RNA; lane 2, pig intestine RNA (30 $\mu \mathrm{g}$, negative control); lane 3, LPS-stimulated human peripheral blood leukocyte RNA ( $8 \mu \mathrm{g}$, positive control); lane 4, untreated HFK RNA (18 $\mu \mathrm{g})$; lane 5, HFK, treated with $100 \mathrm{~mJ} / \mathrm{cm}^{2}$ of UVB and harvested after $1 \mathrm{~h}(18 \mu \mathrm{g})$; lane 6, HFK treated with 100 $\mathrm{mJ} / \mathrm{cm}^{2}$ of UVB and harvested after $6 \mathrm{~h}(18 \mu \mathrm{g})$; lane $7, \mathrm{HFK}$, $200 \mathrm{~mJ} / \mathrm{cm}^{2}, 1 \mathrm{~h}(18 \mu \mathrm{g})$; lane 8 , HFK, $200 \mathrm{~mJ} / \mathrm{cm}^{2}, 6 \mathrm{~h}(18 \mu \mathrm{g})$; lane $9, \mathrm{HFK}, 300 \mathrm{~mJ} / \mathrm{cm}^{2}, 1 \mathrm{~h}$ (18 $\mu \mathrm{g})$; lane 10, HFK, $300 \mathrm{~mJ} /$ $\mathrm{cm}^{2}, 6 \mathrm{~h}(18 \mu \mathrm{g}) . M$, marker, pBR 322 Hinf I.

200 or $300 \mathrm{~mJ} / \mathrm{cm}^{2}$; however, these amounts of UVB led to an 8- to 17-fold increase in both IL-1 mRNAs by $6 \mathrm{~h}$ after irradiation (Fig. 4 and Table I). To determine the specificity of this increase in IL-1 mRNA after UVB irradiation, we examined total RNA from the same samples using a cDNA probe for actin. Fig. 5 shows a slot blot analysis of three of these RNAs from which relative values for actin mRNA levels were extrapolated by linear regression analysis. Levels of actin mRNA did not change significantly after exposure to UVB irradiation, even under conditions where IL-1 mRNA was markedly increased (i.e., 200 $\mathrm{mJ} / \mathrm{cm}^{2}$ at $6 \mathrm{~h}$ ). Thus, the UVB-induced increase of IL-1 mRNA

Table I. Comparison of IL-1 Biological Activity and $m R N A$ in UVB Irradiated Human Keratinocytes

\begin{tabular}{|c|c|c|c|c|c|}
\hline \multirow[b]{2}{*}{ UVB } & \multirow[b]{2}{*}{$\begin{array}{l}\text { Biological } \\
\text { activity }\end{array}$} & \multicolumn{2}{|c|}{$\mathrm{IL}-1 \boldsymbol{\alpha}$} & \multicolumn{2}{|c|}{ IL- $1 \beta$} \\
\hline & & $1 \mathrm{~h}$ & $6 \mathrm{~h}$ & $1 \mathrm{~h}$ & $6 \mathrm{~h}$ \\
\hline \multicolumn{6}{|l|}{$\mathrm{mJ} / \mathrm{cm}$} \\
\hline None & 1.0 & 1.0 & 1.0 & 1.0 & 1.0 \\
\hline 100 & 1.4 & 2.7 & 1.0 & 1.8 & 2.3 \\
\hline 200 & 2.2 & 1.4 & 8.0 & 1.5 & 13 \\
\hline 300 & 7.3 & 1.9 & 10 & 2.5 & 17 \\
\hline
\end{tabular}

Comparison of relative increases in biological activity (D10 assay, see Fig. 6) and levels of IL-1 and mRNA after UVB irradiation (see Fig. 4). Increases in IL-1 activity were calculated by dividing total IL-1 units per culture induced by different UVB doses by total IL-1 activity from uninduced cultures. Relative amounts of IL-1 and mRNA were calculated as described in Methods, and relative quantities of IL-1 mRNA in cells harvested 1 and $6 \mathrm{~h}$ after UVB irradiation were compared to relative quantities of IL-1 mRNA in uninduced cells. is not paralleled by a general nonspecific accumulation of actin mRNA.

Keratinocyte IL-1, like macrophage and monocyte IL-1, is present both in tissue culture medium as a secreted protein and, in substantial quantities, as a cell-associated protein (24, and unpublished observations). We have previously shown that the ability of keratinocyte conditioned medium to stimulate D10 proliferation can be completely neutralized by specific antibodies to IL- $1 \alpha$ and $\beta$ (9). Since quantitation of culture medium IL-1 alone disregards the cell-associated compartment, and since cellular injury and passive release of IL- 1 by the cell could result in a spurious increase in supernatant IL-1 activity without de novo synthesis of IL-1, both secreted and cell-associated fractions from HFKs exposed to UVB irradiation were tested for IL-1 activity. The assay involving costimulation of

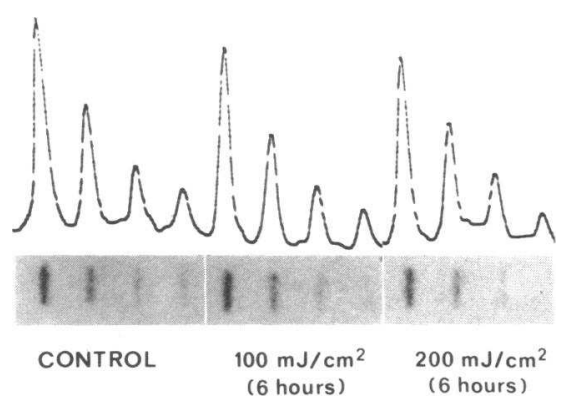

Figure 5. Slot blot analysis to determine relative levels of actin mRNA in three of the RNA samples analyzed in Fig. 1. The lower portion of the figure shows the autoradiogram of the slot blots. For each sample, from left to right were loaded $6,3,1.5$, and $0.75 \mu \mathrm{g}$ of total RNA. The upper portion shows the scan of the film at $550 \mathrm{~nm}$. 
D10, a cloned $\mathrm{T}$ helper cell, in the presence of a monoclonal clonotype specific antibody (3D3), was used to quantify IL-1 activity (22). Fig. 6 shows that extracellular IL-1 activity is detectable in the absence of apparent stimulation, but that the majority of IL-1 activity is cell associated. IL-1 activity increases significantly as a function of the amount of UVB energy delivered to the cells, reflected in a proportional increase in IL1 activity in both extracellular and cell-associated compartments. This indicates that the UVB-induced increase in secreted IL-1 observed here and previously by other (14) does not simply reflect a shift in IL-1 compartmentalization. These data also suggest that most of the IL-1 produced by cultured keratinocytes, even after UVB irradiation, is not secreted but rather remains in a cell-associated compartment. The present study does not address the issue of putative shifts between cytoplasmic and membrane-bound compartments. Total IL-1 (secreted plus cell associated) is significantly increased by exposure to UVB energies that also cause the accumulation of IL-1 mRNA (but not actin mRNA) in keratinocytes (Table I).

\section{Discussion}

We have shown that keratinocytes contain mRNAs identical to the mRNAs encoding monocytic IL-1 $\alpha$ and $\beta$ by S1 nuclease protection analysis, indicating the ETAF represents a mixture of IL- $1 \alpha$ and $\beta$. Once again, the finding of substantial quantities of IL-1 $\alpha$ mRNA in human keratinocytes confirms our previous findings (9) and indicates that IL-1 $\alpha$ is not properly regarded as a minor form of IL-1 in man. The presence of substantial IL-1 mRNA and IL-1 bioactivity in cultures of unstimulated keratinocytes is of considerable interest. Unstimulated monocytes contain virtually undetectable IL-1 mRNA and IL-1 activity, and only express IL-i mRNA after appropriate stimulation (3, 4). Human stratum corneum, however, contains significant IL1 activity (25); this IL-1 from terminally differentiated nonviable keratinocytes is excreted by the natural desquamation of stratum corneum and may represent a reservoir of preformed IL-1 in vivo. The quantity of IL-1 found in this compartment suggests that constitutive IL-1 production by keratinocytes occurs in vivo as well as in vitro. Similar findings were recently reported by Hauser et al., who found that ETAF/IL-1 activity could be dem-

\begin{tabular}{|c|c|c|c|}
\hline \multicolumn{2}{|c|}{ EXTRACELLULAR } & \multicolumn{2}{|c|}{ CELL-ASSOCIATED } \\
\hline$(8)$ & & $300 \mathrm{~mJ} / \mathrm{cm}^{2}$ & (92) \\
\hline & $(5)$ & $200 \mathrm{~mJ} / \mathrm{cm}^{2}$ & (95) H \\
\hline & $(3)$ & $100 \mathrm{~mJ} / \mathrm{cm}^{2}$ & (97) \\
\hline & (3) & none & (97) \\
\hline 20 & 10 & 1.0 & 20 \\
\hline
\end{tabular}

Figure 6. Aliquots of secreted (medium) and cell associated (freezethaw lysate) as well as serial fivefold dilutions of each, were mixed with D10 cells and 3D3 antibody as described in Methods. All samples were tested in triplicate. Units of IL-1 activity were calculated as the reciprocal of the dilution yielding $1 / 2$ maximal proliferation as previously described (22). All groups are significantly different at (at least) a $P$ value of $<0.001$. The percent total IL-1 activity is shown in parentheses within each bar. onstrated in unstimulated human epidermis but not in unstimulated peripheral blood monocytes (26).

TPA has been shown to increase IL-1 activity in cultures of macrophages and keratinocytes $(12,27)$. However, phorbol esters may act as agonists of IL-1 activity on various cells (7), and it has been difficult to separate agonist from inducer activities using standard IL-1 bioassays. The data presented here suggest that TPA specifically elevates IL- $1 \alpha$ and $\beta$ mRNAs in cultured human keratinocytes. This indicates that although appreciable levels of $\mathrm{IL}-1 \alpha$ and $\beta$ mRNAs can be found in populations of human keratinocytes in the absence of intentional stimulation, further increases in the levels of these mRNAs can be induced in such cell populations. Subsequent studies to determine the mechanism by which TPA enhances IL-1 mRNA levels are underway.

The present study shows that environmentally relevant UV irradiation increases both IL-1 mRNA and protein in a dosedependent fashion in cultured keratinocytes. Doses of 200 and $300 \mathrm{~mJ} / \mathrm{cm}^{2}$ are most efficient in this regard. Incidentally, it was noted that identical energies of unfiltered artificial UVB light lethally injured cells; this is consistent with the observation that significant damage of cellular DNA induced by wavelengths of 290-300 nm, which are normally filtered by the atmosphere (17). Significant accumulation of IL-1 mRNAs does occur by 1 $\mathrm{h}$ postirradiation; however, at $6 \mathrm{~h}$, both IL $1 \alpha$ and $\beta$ mRNAs increase substantially over control values. IL-1 bioactivity is increased as early as $2 \mathrm{~h}$ after UVB irradiation (not shown), and substantial increases in both extracellular and cell-associated fractions are seen after $24 \mathrm{~h}$. The data are consistent with the idea that UVB irradiation leads to an increase in the steady state levels of both IL- $1 \alpha$ and $\beta$ mRNA, as well as IL-1 protein, in cultured human keratinocyte populations. No significant shift in the cellular compartmentalization of IL-1 is induced by UVB irradiation; that is, keratinocyte IL-1, at least in cells cultured in this fashion, is predominantly a cell-associated protein.

The mechanism by which IL- $1 \alpha$ and $\beta$ mRNA is elevated in a population of cultured human keratinocytes by UVB or by TPA cannot be determined from this study. However, it is unlikely that UVB irradiation leads to nonspecific stabilization of all cellular mRNAs by interfering with mRNA degradation, since another mRNA (actin) that is produced constitutively by keratinocytes is not affected by UVB irradiation. It is possible that UVB irradiation induces events that cause selective stabilization of certain mRNAs including IL- $1 \alpha$ and $\beta$; alternatively, it is possible that such events enhance transcription of the IL-1 genes. Experiments are in progress to evaluate these possibilities. However, we cannot rule out the possibility that only a small fraction of cells in uninduced keratinocyte cultures contain IL-1 mRNAs, and that UVB irradiation leads to events that increase the proportional representation of such cells. This possibility is currently being addressed by in situ hybridization studies of cultured human keratinocytes.

Studies using a murine model of in vivo UVB irradiation have shown that by $24 \mathrm{~h}$ after 3 MED of UVB, a mixed inflammatory cell infiltrate can be observed in the upper dermis (28). Application of TPA to mouse epidermis induces identical changes in the histology of skin (29). Interleukin 1 production by keratinocytes has been implicated in the recruitment of inflammatory cells to skin, and injection of either purified epidermal IL- 1 or recombinant IL- $1 \alpha$ induces a similar inflammatory infiltrate (30). By $48 \mathrm{~h}$ after treatment with UVB or TPA, an increase in the thickness of epidermis can be observed 
that can be accounted for by proliferation of keratinocytes in situ; similarly, IL-1 has been implicated in the autocrine growth of keratinocytes $(30,31)$. Both UVB and TPA have been shown to induce ornithine decarboxylase activity, which is important in the synthesis of polyamines (32), and this has been cited as evidence that UVB and TPA share tumor promoting activities, since polyamines have been implicated in both normal cell growth and malignant transformation $(33,34)$. The importance of the observation that both stimuli also induce the accumulation of IL-1 mRNA and protein in keratinocytes is unknown at present.

The observation that UVB irradiation causes a graded increase in both the accumulation of IL-1 mRNA and protein in human keratinocytes suggests that many of the immediate biological responses to excessive sun exposure may be mediated by keratinocyte IL-1. These include local effects such as enhanced prostaglandin synthesis by epidermal cells, fibroblast activation $(5,6,10,25)$, and recruitment of neutrophils and $T$ cells from peripheral blood (35), all of which can be mediated or influenced by IL-1 and may be important in the repair of injured tissue. Certain systemic effects seen after excessive sun exposure can be mediated by IL-1 as well, including fever, leukocytosis, and the acute phase response. UVB can injure cells by a variety of different mechanisms (17), and it is not clear what elements UVB irradiation and other injurious IL-1 inducing stimuli share.

UVB irradiation is considered immunosuppressive; antigen presentation of Langerhans cells is inhibited in UVB exposed skin and suppressor $\mathrm{T}$ cell circuits are activated in response to antigen recognized in this context (36). Thus, it seems paradoxical that IL-1, a molecule vital to successful antigen presentation to $T$ helper cells, should increase in this setting. A possible explanation is that since UVB irradiation constitutes an injury to skin, it may be important to inhibit antigen presentation of UVB altered tissue that could provoke an autoimmune response. IL1 may thus be produced in this context primarily to mediate inflammation and healing, and not to augment antigen-specific immune responses. Defective antigen presentation and locally suppressed immunity may help subserve the successful resolution of an inflammatory injurious process.

The presence of significant amounts of IL-1 in human epidermis, coupled with a mechanism of regulating the expression of IL-1 genes in response to a ubiquitous environmental stimulus, suggests that the keratinocytes may strongly influence the biological consequences of solar radiation injury.

\section{References}

1. Auron, P. E., A. C. Webb, L. J. Rosenwasser, S. F. Mucci, A. Rich, S. M. Wolff, and C. A. Dinarello. 1984. Nucleotide sequence of human monocyte IL-1 precursor cDNA. Proc. Natl. Acad. Sci. USA. 81: 7907-7911.

2. March, C. J., B. Mosely, A. Larsen, D. P. Cerretti; G. Braedt, V. Price, S. Gillis, C. S. Henney, S. R. Kronheim, K. Grabstein, P. J. Conlon, T. P. Hopp, and D. Cosman. 1985. Cloning, sequence, and expression of two distinct human interleukin 1 complementary DNAs. Nature (Lond.). 315:641-647.

3. Kilian, P. L., K. L. Kaffka, A. S. Stern, D. Woehle, W. R. Benjamin, T. M. DeChiara, U. Gubler, J. J. Farrar, S. B. Mizel, and P. T. Lomedico. 1986. Interleukin $1 \alpha$ and interleukin $1 \beta$ bind to the same receptor on $\mathrm{T}$ cells. J. Immunol. 136:4509-4514.

4. Dower, S. K., S. R. Kronheim, T. P. Hopp, M. Cantrell, M. Delly, S. Gillis, C. S. Henney, and D. L. Urdal. 1986. The cell surface receptor for interleukin $1 \alpha$ and interleukin $1 \beta$ are identical. Nature (Lond.). 234: 266-267.

5. Oppenheim, J. J., E. J. Kovacs, K. Matsushima, and S. K. Durum. 1986. There is more than one interleukin 1. Immunol. Today. 7:45-56. 6. Dinarello, C. A. 1984. Interleukin 1. Rev. Infect. Dis. 6:51-93.

7. Durum, S. K., J. A. Schmidt, and J. J. Oppenheim. 1985. Interleukin 1: an immunological perspective. Annu. Rev. Immunol. 31:263298.

8. Luger, T. A., B. M. Stadler, S. I. Katz, and J. J. Oppenheim. 1981. Epidermal cell (keratinocyte) derived thymocyte activating factor. J. Immunol. 127:1493-1499.

9. Kupper, T. S., D. W. Ballard, A. O. Chua, J. McGuire, P. M. Flood, M. C. Horowitz, R. Langdon, L. Lightfoot, and U. Gubler. 1986. Human keratinocytes contain mRNA indistinguishable from monocyte interleukin $1 \alpha$ and $\beta$ mRNA: Keratinocyte epidermal cell derived thymocyte activating factor is identical to interleukin 1. J. Exp. Med. 164: 2095-2100.

10. Sauder, D. N. 1985. Biologic properties of epidermal cell thymocyte activating factor (ETAF). J. Invest. Dermatol. 85:1765-1772.

11. Kupper, T., J. McGuire, and L. Lightfoot. 1985. The effect of UVB, UVC, and temperature elevation to $42^{\circ} \mathrm{C}$ on the production of ETAF. J. Invest. Dermatol. 8:342(a). (Abstr.)

12. Luger, T. A., B. M. Stadler, B. M. Luger, B. J. Matheison, M. Maye, J. A. Schmidt, and J. J. Oppenheim. 1982. Murine epidermal cell thymocyte activating factor resembles murine interleukin 1 . J. Immunol. 128:2147-2152.

13. Gery, I., and J. L. Lepe-Zuniga. 1984. Interleukin 1: uniqueness of its production and spectrum of activities. Lymphokines. 9:109-127.

14. Ansel, J. C., T. A. Luger, and I. Green. 1983. The effect of in vitro and in vivo UV irradiation on the production of ETAF activity by human and murine keratinocytes. J. Invest. Dermatol. 81:619-624.

15. Stingl, L. A., D. N. Sauder, M. lijima, K. Wolff, H. Pehamberger, and G. Stingl. 1983. Mechanism of UVB induced impairment of the antigen presenting capacity of murine epidermal cells. J. Immunol. 130: $1586-1592$.

16. Gahring, L. C., M. Baltz, M. B. Pepys, and R. A. Daynes. 1984. The effect of ultraviolet radiation on the production of ETAF/IL-1 in vitro and in vivo. Proc. Natl. Acad. Sci. USA. 81:1198-1202.

17. Regan, J. D., and J. A. Parrish, editors. 1982. The Science of Photomedicine. Plenum Press, New York.

18. Setlow, R. B. 1974. The wavelengths in sunlight effective in producing skin cancer: a theoretical analysis. Proc. Natl. Acad. Sci. USA. 71:3363-3367.

19. Olson, R. I., R. M. Sayre, and M. A. Everett. 1966. Effect of anatomic location and time on ultraviolet erythema. Arch. Dermatol. 93:211-217.

20. Rheinwald, J. G., and H. Green. 1975. Serial cultivation of strains of human epidermal keratinocytes: the formation of keratinizing colonies from single cells. Cell. 6:331-338.

21. Kaye, J., S. Gillis, S. B. Mizel, E. M. Shevach, T. R. Malek, C. A. Dinarello, L. B. Lachman, and C. A. Janeway, Jr. 1984. Growth of a cloned $\mathrm{T}$ helper cell line induced by monoclonal antibody specific for the antigen receptor: interleukin 1 is required for the expression of receptors to interleukin 2. J. Immunol. 133:1339-1345.

22. Kaye, J., and C. Janeway, Jr. 1984. Induction of receptors for interleukin 2 requires $\mathrm{T}$ cell antigen Ia receptor crosslinking and interleukin 1. Lymphokine Res. 3:175-182.

23. Gubler, U., A. O. Chua, A. S. Stern, C. P. Hellman, M. D. Vitek, T. M. DeChiara, W. R. Benjamin, K. J. Collier, M. Dukovich, P. C. Familletti, et al. 1986. Recombinant human interleukin $1 \alpha$ : purification and biological characterization. J. Immunol. 136:2492-2497.

24. Goldminz, D., T. S. Kupper, and J. McGuire. 1987. Keratinocyte membrane associated epidermal cell derived thymocyte activating factor (ETAF). J. Invest. Dermatol. 88:97-100.

25. Gahring, L. C., A. Buckley, and R. A. Daynes. 1985. The presence of ETAF/IL-1 in normal human stratum corneum. J. Clin. Invest. 76: 1585-1594. 
26. Hauser, C., J. H. Saurat, A. Schmitt, F. Jaunin, and J. M. Dayer. 1986. Interleukin 1 is present in normal human epidermis. J. Immunol. 136:3317-3321.

27. Mizel, S. B., and D. J. Mizel. 1981. Purification to apparent homogeneity of interleukin 1. J. Immunol. 126:834-837.

28. Lowe, N. J. 1981. Ultraviolet light and epidermal polyamines. J. Invest. Dermatol. 77:147-154.

29. Koury, M. I., A. Balmian, and I. B. Pragnell. 1983. Induction of granulocyte macrophage colony stimulating activity in mouse skin by inflammatory agents and tumor promoters. EMBO J. 2:1877-1883.

30. Granstein, R. D., R. Margolis, S. B. Mizel, and D. N. Sauder. 1986. In vivo inflammatory activity of epidermal cell derived thymocyte activating factor and recombinant interleukin 1 in the mouse. J. Clin. Invest. 77:1020-1026.

31. Gilchrist, B., and D. N. Sauder. 1984. Autocrine growth stimulation of human keratinocytes by epidermal cell derived thymocyte ac- tivating factor (ETAF): implications for cellular ageing. J. Invest. Dermatol. 82:439(a). (Abstr.)

32. O'Brien, T. G., R. C. Simsiman, and R. K. Boutwell. 1976. Induction of the polyamine biosynthetic enzymes in mouse epidermis by tumor promoting agents. Cancer Res. 35:1662-1667.

33. Janne, J., H. Poss, and A. Paine. 1978. Polyamines in rapid growth and cancer. Biochem. Biophys. Acta. 473:241-248.

34. O'Brien, T. G. 1976. The induction of ornithine decarboxylase as an early, possibly obligatory, event in mouse skin carcinogenesis. Cancer Res. 36:2644-2648.

35. Sauder, D. N., M. M. Monick, and G. W. Hunninghake. 1985. Epidermal cell derived thymocyte activating factor (ETAF) is a potent T cell chemoattractant. J. Invest. Dermatol. 85:431-437.

36. Granstein, R. D., A. Lowy, and M. I. Greene. 1984. Epidermal antigen presenting cells in activation of suppression: identification of a new functional type of ultraviolet radiation resistant epidermal cell. Immunol. 132:563-568. 